\title{
University of Plymouth
}

PEARL

https://pearl.plymouth.ac.uk

Faculty of Science and Engineering

School of Geography, Earth and Environmental Sciences

2012-07-18 
Revised Version 3

(incorporating final queries of the Editors)

\section{Green Revolution and its Factor Market Effects in Bangladesh}

\section{Sanzidur Rahman}

School of Geography, Earth and Environmental Sciences, University of Plymouth, UK

\section{Ismat Ara Begum}

Department of Agricultural Economics, Ghent University, Belgium and Department of Agricultural Economics, Bangladesh Agricultural University, Bangladesh

\section{Mohammad Jahangir Alam}

Department of Agricultural Economics, Ghent University, Belgium and Department of Agribusiness and Marketing, Bangladesh Agricultural University, Bangladesh

\section{$\underline{\text { Address for correspondence }}$}

Dr. Sanzidur Rahman

Associate Professor in Rural Development

School of Geography, Earth and Environmental Sciences

University of Plymouth

Drake Circus

Plymouth, PL4 8AA

Phone: +44-1752-585911

Fax: +44-1752-585998

E-mail:srahman@plymouth.ac.uk

June 2011 


\title{
Green Revolution and its Factor Market Effects in Bangladesh
}

\begin{abstract}
Although the literature on socio-economic impacts of green revolution (GR) technology is abundant, these are largely drawn from its earlier stages of diffusion (i.e., 1960s-1980s) and the findings are inconclusive and vary across geographical regions. The present paper empirically re-examines the effect of GR technology on the factor markets at its mature stage of diffusion in Bangladesh using a holistic framework which allows for simultaneous determination of factors influencing adoption of GR technology as well as access to irrigation. Results reveal alignment with conventional wisdom as well as few surprises. For example, although GR technology has increased demand for major inputs as expected, but has also increased demand for organic manures, an unexpected but positive outcome. The GR adoption rate is significantly higher in villages endowed with access to irrigation and fertile soils as expected but surprisingly, it is also higher in infrastructurally underdeveloped villages. Rise in cereal price boost GR adoption as expected. Expansion of irrigation is influenced by access to credit, tenurial status and fertile soils as expected. Policy implication includes investment in irrigation, soil conservation as well as measures to improve cereal prices and agricultural credit to boost GR technology adoption.
\end{abstract}

Key words: GR technology, factor market effects, determinants of adoption, simultaneous equations system, Bangladesh

JEL classification: Q12, O33, C31 


\section{Introduction}

The twentieth century experienced a major breakthrough in agricultural history owing to the development of high yielding varieties (HYV) of wheat and rice during the 1950s and 1960s, which are highly responsive to inorganic fertilizers, pesticides, effective soil management and water control (Singh 2000). The high returns (reportedly) associated with the adoption of these new varieties of rice and wheat (and maize to some extent) led to their rapid diffusion in countries of Asia and Latin America (much later in Africa) consequently leading to a dramatic increase in food production. The spread of this technology, popularly coined as the 'Green Revolution $^{1}$ (hereafter GR) technology (Tsubota 2002) has been the fastest of all in the history of technological innovations in agriculture and was acclaimed as the most successful achievement in international development efforts that transformed millions of poor people's lives (Lipton and Longhurst 1989; Wolf 1986).

Agriculture is the major source of livelihood in Bangladesh accounting for 23.5\% of national income and employs $62 \%$ of the labour force (MoA 2008). The dominant sector is the field crop agriculture accounting for more than $60 \%$ of agricultural value added. Among the field crops, rice is the major staple occupying 79\% of the gross cropped area (Rahman 2010). Historically, being a food deficit country, Bangladesh has pursued a policy of rapid technological progress in agriculture. Consequently, over the past four decades, major thrust of the national policies were directed towards transforming agriculture through rapid technological progress to keep up with the increasing population. Development programs were undertaken to diffuse HYV rice and wheat with corresponding support in the provision of modern inputs such as, chemical fertilizers, pesticides, and irrigation equipments and other rural infrastructures, institutional credit, product procurement, storage and marketing facilities. This has led to an increase in fertilizer use from only 14.25 kilogram $(\mathrm{kg})$ of nutrients per ha in 1973 to a staggering 127.18 
$\mathrm{kg}$ of nutrients per ha in 2006, pesticide use from only $0.26 \mathrm{~kg}$ of active ingredients per ha in 1977 to $1.23 \mathrm{~kg}$ of active ingredients per ha in 2002 , and proportion of irrigated area from only $11.0 \%$ of gross cropped area in 1973 to $37.5 \%$ in 2006, respectively (Rahman 2010).

There is a very large body of literature on GR covering several dimensions of this complex technology package. Most of the evaluations (earlier as well as later ones ${ }^{2}$ ) largely concentrated on the impacts of GR on agricultural productivity, economic growth, employment, income, equity (distribution of income) and poverty with mixed results (e.g., Douglas et al. 2005; Evenson and Douglas 2003; Rahman 1999; Freebairn 1995; Hazell et al. 1991; Alauddin and Tisdell 1991; Hossain et al. 1990; Hossain 1989; Lipton and Longhurst 1989). Delayed consequences of GR technology on the environment and the question of sustainability of agricultural growth received priority only recently (Singh 2000; Shiva 1991; Alauddin and Tisdell 1991; Redclift 1989). Singh (2000) identified widespread adoption of GR technologies as a cause of significant soil degradation in Haryana state of India. Pimentel (1996) clearly indicated that the extensive use of fertilizers and pesticides to support the GR has caused serious public health and environmental problems and chemical pollution costs an estimated $\$ 100$ billion each year in public health and environmental damages worldwide. Antle and Pingali (1994) in their case study in Philippines, concluded that pesticide use (apparently to support GR) has an adverse impact on farmer health, and that the impairment of farmer health reduces productivity. Shiva (1991) in her analysis of agricultural transformation in Indian Punjab concluded that the GR produced scarcity and not abundance by reducing the availability of fertile land and genetic diversity of crops. Redclift (1989) examining the issues of environmental degradation in rural areas of Latin America noted that it is closely related to agricultural modernization 
However, historical analysis revealed that productivity from GR is declining and now poses a threat to sustainability of economic development (Janaiah et al. 2005; Ladha et al. 2003; Coelli et al. 2002; Ali and Byerlee 2002; Rahman 2002; Pingali et al. 1997; Alauddin and Tisdell (1991). During the first phase (1960-1980) of GR diffusion, the total rice output of the nation grew at an annual rate of $2.2 \%$ and then reduced to half the previous rate at $1.1 \%$ during $1988-1997$ (Otsuka 2000). In fact, the yield rate of modern rice steadily declined from $3.6 \mathrm{mt} / \mathrm{ha}$ in $1968 / 69$ to $2.4 \mathrm{mt} /$ ha in $1993 / 94$, with an estimated annual rate of decline of $1.2 \%$ (Rahman 2002). However, Rahman (2010) noted that the yield rate of HYV rice has reversed during the mature stage of GR (1981-2006) and has been growing at an annual rate of $1.4 \%$.

As with the national level results, the farm level evaluations of the impacts of GR in Bangladesh were also mixed. Some early evaluations of GR confirmed its production, employment and income generating potential accompanied with either neutral or marginally negative income distribution effect as well as significant reduction in the incidence of rural poverty (Hossain 1989; Hossain et al. 1990). It was argued that the poor gained in absolute terms through the operation of the labour market, if not from the direct adoption of GR technology, owing to increased demand for labour and higher wages plus dampening real rice prices owing to increased productivity (Hossain 1989; Hossain et al. 1990; Ahmed 2000). On the other hand, others argued that the relative share of labour has fallen and there is limited potential to further absorb labour, which exhibits wide inter-seasonal disparities in employment and farmers' welfare did not improve with the adoption of this new technology (Evenson and Douglas 2003; Islam and Taslim 1996; Alauddin and Tisdell 1995).

As a result of such controversies, it was felt necessary to empirically re-examine the arguments put forward in favour of promoting GR technology in developing economies at its mature stage of diffusion. Specifically, the present study re-examines the following: (1) the effect of GR 
technology diffusion on the factor/input markets (i.e., labour, animal power services, inorganic fertilizers, pesticides and organic manures); (2) the determinants of the adoption of GR technology; and (3) the determinants of irrigation access/expansion (a key pre-requisite for the diffusion of GR technology).

The importance of analyzing factor/input market effect of GR technology arises due to the fact that market development is crucial in supporting GR technology because of its input intensive nature, and most of which needs to be sourced from off-farm and/or industrial sources. During the 1960s and 1970s, GR technology diffusion succeeded in Asia because governments provided the required inputs and services through high level of subsidies, marketing infrastructure by setting parastatal organisations, and extension and research support (Crawford et al., 2003). However, later it was realized that such high level of subsidies and support are financially unsustainable in the long run, create macro-economic problems and are less effective in raising farmers' access to required inputs (Bates, 1981 cited in Crawford et al., 2003). This led to dismantling of parastatals and removal of subsidies through structural adjustment policies in many developing countries (Crawford et al., 2003). Similarly, Bangladesh also moved out from state controlled policies of 1970 s and 1980 s to market oriented approaches in 1990s following the recommendation of the World Bank and IMF (Salim and Hossain, 2006). The key elements in these reforms include deregulation and/or removal of input subsidies (particularly fertilizers and irrigation equipments) and output price support, reorganizing the food distribution system and realigning market incentives for greater involvement of the private sector (Salim and Hossain, 2006).

Our key aim in this study is to see whether the demand for inputs at the farm-level owing to GR technology adoption is still evident under a liberalized market scenario in Bangladesh? If such evidence exists, this implies existence of input markets which are at least functional. This 
is because the private sector had not filled the void left by the governments following market reforms, except only in situations where there was clear effective demand for inputs (Donovan, 1996, FAO, 1994). Others claimed that elimination of state-led input promotion programs and limited entry of private sectors have actually led to decline in input use, particularly fertilizers (Bumb and Baanante, 1996) although there is a consensus that increased use of inputs (particularly quality seeds and fertilizers, i.e., the GR ingredients) are essential for agricultural development and food security (Rosegrant et al., 2001).

Given this backdrop, we implement our study by utilising a framework that allows for joint examination of all our three objectives using a simultaneous equations system not commonly seen in the existing literature.

The remainder of the paper is divided into three sections. Section 2 describes the data, the theoretical framework and the empirical model. Section 3 presents the results. The final section discusses and draws policy implications.

\section{Methodology}

\subsection{Data and the study area}

The study is based on farm-level cross section data for crop year 1996 collected from three agro-ecological regions of Bangladesh. The survey was conducted from February to April 1997. Samples were collected from the Jamalpur Sadar sub-district of Jamalpur district, the Manirampur sub-district of Jessore district and the Matlab sub-district of Chandpur.

The justification of selecting these regions is as follows. Jamalpur district, falling within the greater Mymensingh region and located $182 \mathrm{~km}$ northwest from the capital Dhaka, is the official agricultural district of the country characterized by high cropping intensity. The region is well served by large river system as well as developed underground irrigation facilities. Also, the region depicts wet agroecology with high annual rainfall (1820 $\mathrm{mm}$ in 1996). Chandpur district, 
belonging to greater Comilla region and located $120 \mathrm{~km}$ southeast from the capital Dhaka, is an agriculturally developed area where GR technology was first initiated during the early 1960s. The region is also served by a number of river system and well developed irrigation infrastructure. For example, some of the sampled villages are within the Meghna-Dhonagoda Flood Control Drainage and Irrigation $(\mathrm{FCD} / \mathrm{I})$ project. The region also depicts wet agroecology with very high annual rainfall (2036 mm in 1996). Finally, Jessore district, located $294 \mathrm{~km}$ southwest from the capital Dhaka, is characterized by high level of crop diversity. The river system is remote and underground irrigation system is not very well developed. Also, the region depicts dry agroecology with low annual rainfall (1446 $\mathrm{mm}$ in 1996). Therefore, these three regions capture the diverse nature of the production environment within which farming in Bangladesh takes place.

Multistage random sampling technique is employed to locate the districts, then the Thana (subdistricts), the villages in each of the three subdistricts, and finally the sample households. A total of $406^{3}$ households from 21 villages (distributed into 175 households from eight villages of Jamalpur Sadar Thana, 105 households from six villages of Manirampur Thana, and 126 households from seven villages of Matlab Thana) form the sample for the study. Detailed crop input-output data at the plot level for individual farm households are collected for ten crop groups ${ }^{4}$. The dataset also includes information on the level of infrastructural development in the study villages. Of these 406 survey farms, 380 farms produced modern varieties of rice. In our factor market analysis we include both GR and non-GR crops in order to identify the effect of GR technology on the total amount of inputs used for all the crops that the farmers produced in one calendar year. The average number of crops produced are 3.57 (HYV rice and local rice grown in all three seasons are treated as two different crops only, i.e., season is not differentiated) with a maximum of 11 crops produced per year. 
Although the data collected for this study are 14 years old, little has changed with regard to the farming practices, operating institutions, and factor markets in Bangladesh over this period, except for an increase in the level of modern rice technology adoption from $39 \%$ of gross cropped area in 1996 to $57 \%$ in 2007 (MoA, 2008). However, the overall share of total rice area (traditional + modern varieties) remained unchanged at around at $76 \%$ of GCA between these two periods. Also, when econometric modelling framework is used (as discussed below), the results capture the underlying relationships amongst variables which are invariant to the timing of data collection. Therefore, we argue that our results are capable of providing valuable information of relevance to policy makers and development practitioners alike.

\subsection{Theoretical framework}

To examine the determinants of input demand (and hence effect on the factor markets) for producing various crops (including GR crops), a model based on profit maximizing behaviour of the farmers is utilized. Evidence of profit maximizing behaviour of Bangladeshi farmers is well established (e.g., Hossain 1989; Hossain et al. 1990; Ahmed and Hossain, 1990; Rahman 2003).

Assume for simplicity that there are $k$ variable inputs represented by vector $Q$ and one fixed input of land $(L)$ that is allocated between various crops ( $L_{i}$ being the share of total land allocated to the $i$ th crop). These are used to produce $n$ number of crops $(i=1 \ldots n)$ which includes GR crops as well.

Producer $j$ maximizes total profits:

$\sum_{i=1}^{n} p_{i} Y_{i j}-\sum_{i=1}^{n} \sum_{k=1}^{m} w_{k} Q_{i j k}$

s.t. $Y_{i j}=f\left(Q_{i j k}, L_{i j}, S_{j}\right)$ for $i=1 \ldots n, k=1 \ldots m$ 
and $\sum_{i=1}^{n} L_{i j} \leq L_{j}$

where $Q_{i j k}=Q_{i j l}+Q_{j j l}+\ldots .+Q_{\eta j k}$

Eq. (1) is an individual production function for each crop $i$ of producer $j$. It depends on inputs applied to that $\operatorname{crop}\left(Q_{i k k}\right)$, land allocated to that crop $\left(L_{i j}\right)$, and a set of exogenous variables $\left(S_{j}\right)$ that shift the production function. Y's are output quantities, $p$ 's and w's are output prices and input prices. Eq. (2) simply states that land allocated to various crops $\left(L_{i j}\right)$ must be less than the total land $\left(L_{j}\right)$ cultivated by the producer $j$.

The first order conditions will lead to the corresponding set of input demand functions for an individual crop $i$ for producer $j$ :

$$
\sum_{k=1}^{m} Q_{i j k}=Q_{i j k}\left(w_{1} \ldots . w_{m}, p_{i}, L_{i j}, S_{j}\right)
$$

We can aggregate the input demand functions of all individual crops for producer $j$ as follows:

$$
\sum_{i=1}^{n} \sum_{k=1}^{m} Q_{i j k}^{*}=Q_{i j k}^{*}\left(w_{1} \ldots . w_{m}, p_{1} \ldots . . p_{n}, L_{i j} \ldots . . L_{n j}, S_{j}\right)
$$

which is equivalent to:

$$
\sum_{i=1}^{n} \sum_{k=1}^{m} Q_{i j k}^{*}=Q_{i j k}^{*}\left(w_{1} \ldots . w_{m}, p_{1} \ldots . . p_{n}, L_{j}, S_{j}\right)
$$

Eq. (5) represents the total demand for $m$ inputs $\left(Q_{i k}\right)$ required to produce $n$ number of crops by producer $j$ which is expressed as a function of input prices, output prices, total land cultivated $\left(L_{j}\right)$, and a set of exogenous factors $\left(S_{j}\right)$.

An efficient estimation procedure will be to estimate this system of equations jointly using a simultaneous equation framework using either Seemingly Unrelated Regression Estimation (SURE) or Three Stage Least Squares (3SLS) procedure where we do not have to impose separability assumption of inputs. In this paper we used 3SLS procedure as 3SLS is the most 
efficient choice because it allows for endogeneity and the independent variables serves as instruments. However, we also checked for the identification criteria ${ }^{5}$.

\subsection{Specification of the technology variable}

Broadly GR technology can be conceived as the utilization of any or all of the following. For example, use of inorganic fertilizers, supplementary irrigation, pesticides, farm power machineries, and HYV seeds, all constitutes part of GR technology. However, the backbone of GR technology is the use of HYV seeds. Adoption of HYV seeds also leads to the application of other modern inputs such as inorganic fertilizers, supplementary irrigation and pesticides in order to reap the full potential benefit of the GR package. Therefore, we have specified a technology index (TECH), defined as the proportion of total area under HYV seeds of rice and/or wheat' grown in all seasons ${ }^{6}$, to isolate the impact of GR adoption ${ }^{7}$ on factor demands. Formally,

$$
T E C H=\frac{\text { Total area under HYV seeds of rice and / or wheat cultivated in a year }}{\text { Total cultivated area in a year }}
$$

\subsection{The empirical model}

For the empirical estimation of the impact of GR technology on factor demands, a total of five variable input demand functions (fertilizer, labour, animal power service, pesticides and organic manure) were postulated. Since a host of socio-economic factors influence adoption of GR technology, a GR adoption determination function is also postulated wherein irrigation access (a major pre-requisite for GR adoption) enters as a regressor. However, in a resource scarce economy like Bangladesh, access to supplementary irrigation is of paramount importance, expensive and depends largely on the socio-economic circumstances of the farmers. Therefore, an irrigation access determination function is also specified.

In order to complete the empirical model, these two technology adoption functions, i.e., the GR adoption function (Eq. 8) and the irrigation access function (Eq. 9) was appended to the set of 
reduced form five input demand equations (Eqs. 7). The system of equations was estimated jointly using a simultaneous equations framework in order to take into account the recursive nature of the relationship amongst the variables of these functions. The full model containing all the system of equations (seven in total), dropping the $j$ th subscript for the farm is written as:

$$
\begin{gathered}
\sum_{k=1}^{5} \ln Q_{k}=\alpha+\sum_{k=1}^{5} \beta_{k} \ln w_{k}+\gamma \ln P^{\prime}+\delta \ln L+\eta \ln I N F R A+\tau \ln S O I L+\lambda T E C H \\
+\phi C R E D I T+\varepsilon_{k} \\
T E C H=\alpha+\gamma \ln P^{\prime}+\delta \ln L+\eta \ln I N F R A+\tau \ln S O I L+\varphi I R R I G+\phi C R E D I T+\sum_{d=1}^{7} \theta_{d} S_{d}+v \\
\text { IRRIG }=\alpha+\eta \ln I N F R A+\tau \ln S O I L+\phi C R E D I T+\sum_{d=1}^{7} \theta_{d} S_{d}+\zeta
\end{gathered}
$$

where, $k=1,2, \ldots .5$, and stands for fertilizers, human labour, animal power services, pesticides and organic manures; $d=1, \ldots, 7$, stands for a set of socio-economic characteristics of the farmer; ln stands for natural logarithm; $Q_{i}$ 's are the total quantities of fertilizers (kg), labour (person-days), animal power services (pair-days), pesticides (100 ml/gm of active ingredients), and organic manures ('OOO kg), respectively; w's are the prices of fertilizers (Taka ${ }^{8} / \mathrm{kg}$ ), labour (Taka/person-day), animal power services (Taka/pair-day), pesticides (Taka/100 ml or gm), and organic manures (Taka/kg), respectively; $P^{\prime}$ is the mean aggregate cereal price (Taka/kg); $L$ is the amount of total land cultivated by the farmer (ha); TECH is the technology index defined earlier (percent); IRRIG is the irrigation index defined as proportion of total cultivated land under modern irrigation' (percent); and CREDIT is the amount of agricultural credit per household ('OOO Taka).

The seven socio-economic characteristics $\left(\mathrm{S}_{\mathrm{d}}\right)$ are: age of the farmer (years); his/her experience in farming (years); his/her education (completed years of schooling); subsistence pressure measured by family size (persons/household); tenancy dummy (value is 1 if owner operator, 0 
otherwise); extension contact dummy (value is 1 if had extension contact in the past one year, 0 otherwise); and proportion of off-farm income in total income of the household (\%).

Two village level variables were also included in the models to isolate the influence of regional or spatial attributes on factor demands as well as decisions regarding GR adoption and irrigation access. These are: INFRA, an index of underdevelopment of infrastructure ${ }^{9}$ (number) and SOIL, an index of soil fertility level ${ }^{10}$ (number). Finally, $\alpha, \beta, \gamma, \delta, \eta, \tau, \lambda$, $\phi$, and $\theta$ are the parameters to be estimated; and $\varepsilon, v$ and $\varsigma$ are error terms.

Inclusion of all these variables is based on the existing literature with similar justification thereof. Fertilizers, labour, animal power services, and pesticides are the four major inputs that are essential in producing any crop and contribute significantly to the total cost of production. We have also included organic manure as an input which seems to have developed a market not seen in Bangladesh in the past. Profit maximizing farmers are expected to respond to and/or adjust their input use levels to changes in the prices of these five major inputs.

Prices of outputs have a direct bearing on the gross revenue earned from producing individual crops. Therefore, producers are expected to respond to changes in the output prices. However, to simplify the modelling structure and avoid collinearity, we have utilized a single variable of a mean aggregate price of all cereals only $P$ (i.e., rice and wheat of both varieties which are not very different in actual prices).

Producers allocate different amounts of land to each crop in a cropping system. Therefore, the influence of an individual crop on input demand cannot be determined a priori, although a positive association with certain crops is expected. However, to simplify the modelling structure and avoid collinearity, land allocated to each crop is aggregated into a single variable of total land cultivated $(L)$ in a year and incorporated in the model. 
Our key variable of interest TECH is incorporated to capture the independent influence of the adoption of GR technology on demand for inputs. Our a priori expectation is that this variable should have a significant positive association with all the input/factor demand equations.

The state of infrastructure, in terms of better transportation and marketing facilities will affect prices (e.g., pesticides, inorganic fertilizers) through transport costs and the profit margins of traders. The prices farmers pay for inputs and receive for outputs include this transportation cost. Also traders' margins are likely to vary across farms and regions, depending on the state of the development of infrastructure. This effect was captured by the index of infrastructural underdevelopment variable (INFRA). Higher soil fertility status implies favourable physical conditions for agricultural production. This in turn would influence the demand for inputs. Therefore the soil fertility index (SOIL) was incorporated to capture the effect of soil quality on input use. Also, both these spatial variables is likely to influence adoption of GR technology as well as access to irrigation, and hence incorporated in those function as well.

The availability of cash may be a determining factor, enabling the producer to purchase various inputs as required. An agricultural credit variable (CREDIT) was incorporated to capture this effect on input demands. Also, credit may influence adoption of GR technology as well as access to irrigation, and hence also included in those two functions.

The education variable (one of $\mathrm{S}_{\mathrm{d}}$ ) was used as a surrogate for a number of factors. At the technical level, access to information will influence the ability adopt GR technology. Access to irrigation opens up an opportunity to adopt GR technology and is an important prerequisite for its expansion. Therefore, area under irrigation (IRRIG) was incorporated to capture its effect on GR adoption.

\section{Results}


Table 1 presents the parameter estimates of the factor demand function, adoption determination function and irrigation access determination function estimated jointly applying 3SLS procedure using NLOGIT 4 software (ESI 2007). The expected sign of all independent variables used in the regression are also presented in Table 1. Most of the coefficients on the variables used in the analysis were significantly different from zero at $10 \%$ level at least, implying a satisfactory fit. The significant $\mathrm{F}$ value for each equation confirms that the model fit is highly satisfactory (Table 1).

\subsection{Factor market effects of GR technology}

All own-input price coefficients are negative, consistent with the theory of demand and most inputs are complement to each other except pesticides and fertilizers, which are substitutes. Since, all price variables are specified in logarithm, the coefficients can be read directly as price elasticities of input demand. For example, the coefficient on the fertilizer price in the fertilizer demand equation is estimated at -0.51 , which is the price elasticity of fertilizer. The implication is that if the price of fertilizer increases by $10 \%$ then the quantity demanded of fertilizers will decrease by approximately $5 \%$. Similarly, all other coefficients can be interpreted in the same way. Table 1 reveals that the price elasticity of input demand is highest for manure $(-2.70)$ which is an unexpected result followed by animal power services at (-0.94), labour at (-0.71) and fertilizers at (-0.51). The elasticity of pesticide price is not significantly different from zero. Aggregate cereal price has a significant influence on demand for animal power services and manures, which is consistent with the expectation, but significant influence of this variable was expected with respect to other inputs as well.

There is an undisputed evidence of the significant influence of cultivated area on input demand, which is expected in a land scarce economy like Bangladesh. The influence of the state of rural infrastructure, however, tells an interesting story. Demand for fertilizers and labour is 
significantly higher in underdeveloped regions whereas pesticide demand is higher in developed regions ${ }^{11}$. This may be due to higher level of GR technology adoption in underdeveloped region (discussed below) that goes against the convention. Use of agricultural credit has a significant influence on pesticide demand only. This may be because pesticide is applied as and when required and could be quite expensive often requiring cash to purchase. Availability of credit eases such cash requirement.

Finally, turning to our key variable of interest, we see that the adoption of GR technology (TECH) significantly increases demand for all five inputs, thereby re-establishing its input use intensity argument including positive impact on employment generation. However, the significant influence of pesticide demand raises concern on the potential health and environmental hazards associated with its overuse as highlighted in the literature (e.g., Pimentel 1996; Singh 2000).

\subsection{Determinants of GR technology adoption}

Results of the GR technology adoption function reveal that irrigation is the principal determinant of GR adoption consistent with expectation. We also see that the adoption of GR technology is negatively related to total cultivated area which is interesting and is at contrast with the literature. The implication is that farmers with limited land resources adopt GR technology in order to maximize income as compared to large farmers.

Also, the adoption of GR technology is significantly higher in underdeveloped region, a finding that goes against the convention and warrants detailed explanation. Conventionally irrigation is considered as improved infrastructure and hence a positive association is always seen, which was also found in our case. But our infrastructural index excludes irrigation (see footnote \# 9). The higher level of GR adoption rate in underdeveloped regions is due to the fact that it provides the best possible option to improve farmers' income as opportunities for either 
producing high valued cash crops or seeking off-farm employment are highly limited. Therefore, given the limited amount of options to choose from, farmers in underdeveloped regions resort to producing HYV rice provided that irrigation facilities exist. Ahmed (1990) found a positive but non-significant influence of infrastructural development on HYV adoption and concluded that the effects of infrastructure are primarily indirect, through prices and technology adoption (i.e. irrigation). The direct effect (of infrastructure) - which is independent of prices and technology is not significant (Ahmed and Hossain 1990).

The adoption of GR technology is higher in villages with fertile soils as expected. Also, higher cereal price prompts GR adoption decision, consistent with expectation. Among the socioeconomic characteristics of the farmers, we see that the older farmers are more likely to adopt GR technology. However, negative influence of overall experience in farming implies that the less experienced farmers are more likely to adopt GR technology which is puzzling. Adoption of GR technology is significantly higher for households that has limited access to non-farm activities and hence income derived from such sources, consistent with expectation.

\subsection{Determinants of irrigation access}

Finally, an examination of the determinants of irrigation access reveals that the demand for irrigation is significantly higher in fertile regions and by the owner operators and is positively influenced by availability of agricultural credit. This is because irrigation fee in Bangladesh is one of the highest typically ranging from Taka $1000-1200$ per acre and/or $25 \%$ of gross output of paddy (Rahman 1998). Demand for irrigation is also significantly higher among households who have limited access to non-farm earning opportunities, implying that farming is their primary livelihood choice.

$<$ Insert Table 1 near here $>$

\section{Discussion and policy implications}


The present study is set out to re-examine the influence of GR technology adoption on the demand for five major production inputs while simultaneously examining factors determining its adoption as well as access to irrigation. Results reveal that GR technology diffusion in the agricultural sector has exerted a distinct upward pressure on input demands including labour use, thereby confirming positive impact on employment generation. Although consequent rise in the demands for inorganic fertilizers and pesticides raises concerns on the sustainability of this technology, the accompanied highly elastic demand for organic manure is a positive but an unexpected outcome. The increased use of organic manure is likely to replenish soils or retain soil fertility to a satisfactory level perhaps. Cereal price improvement also significantly influences GR adoption. Increase in the demand for major inputs, in general, would induce dynamism in the rural economy by promoting trade and allied activities, another major argument in favour of expanding GR technologies. For example, Hazell et al. (1991) noted that each rupee of value added (VA) in agriculture stimulated rupee 0.87 of VA in the region's nonfarm economy in South India.

Our results also reveal that spatial attributes have a significant influence on demand for modern inputs as well as adoption of GR technology but with differential impacts. The demand for modern inputs and GR technology adoption is higher in villages with underdeveloped rural infrastructure (that do not include soil fertility and irrigation facility/accessibility in its construction, see footnote \# 9) which we have explained in relation to lack of opportunities to produce high value non-cereals and/or engagement in non-farm activities as would be possible in developed regions.

Our results also reveal that the input demand is lower in fertile regions while GR adoption is still higher which confirms that the prime determinants of GR adoption are irrigation access and fertile soils even though there may be limited level of other rural infrastructure facilities, 
e.g., road and market access. The lower level of input demand in fertilizer is perhaps related to farmers' knowledge that the soils are fertile and therefore, requires less input which was noted by Rahman and Parkinson (2007). In fact, Payton et al., (2003) noted that farmers can distinguish soil fertility based on feel and visual observations, even in the absence of analytical data. Existing literature do not directly link spatial attributes (e.g., villages with fertile soils) to adoption of GR technology and demand for major inputs (i.e., factor market effects) in a single analysis although it is apparent that these issues are intricately linked.

The following policy implications can be drawn from this study. First, Bangladesh needs investment in irrigation to boost adoption of GR technology. For example, the correlation coefficient between irrigated area and HYV rice area in Bangladesh for the period 1975 to 2006 is estimated at $0.99(\mathrm{p}<0.001)$ which proves the point. Our study also reveals that access to irrigation is significantly influenced by availability of agricultural credit. Therefore, measures to improve access to agricultural credit will result in the expansion of irrigation which in turn will boost adoption of GR technology. Second, subsequent investment in soil conservation measures will have a dual effect of not only significantly increasing GR adoption rate but will also limit increased demand for modern inputs at the same time, which is highly desirable on sustainability ground. Some agronomists raised concerns about the negative impact of structural adjustment policies on soil fertility and agricultural productivity and recommended renewed government support for input promotion programs (Cawford et al., 2003) whereas others argued for a wide range of interventions capable of increasing supply, reducing costs and increasing demand without subsidies (e.g., Reardon et al., 1999; Donovan, 1996; FAO, 1994). Our recommendation mirrors the latter options where improved soil conservation will increase output supply (e.g., Rahman and Parkinson, 2007) and perhaps reduce production costs without requiring subsidies on fertilizers. Third, policies to promote cereal prices will also boost GR 
technology adoption. However, this would increase vulnerability of the rural poor (those largely dependent on agricultural wages) in the short run, as in the longer run agricultural wages rise consistently in response to increase in rice prices, upto the tune of $44 \%$ (PalmerJones and Parikh 1998). Therefore, a broader policy agenda is needed that not only focuses on cereal prices but also promote growth that demands more use of labour and provide safety nets to mitigate food insecurity of the rural poor. Our results show that GR adoption significantly increases labour demand and, therefore, a rise in cereal prices will ultimately benefit the rural poor in terms of generating more employment and consequently with a rise in wages in the long run. In fact, this was one of the key arguments in favour of promoting GR technology diffusion in developing economies, which seems to be still relevant in Bangladesh.

The challenges to realize all of these policy options are formidable. However, targeted investments in these three areas would significantly increase boost GR technology adoption which will ultimately increase food production and generate employment and income within the agricultural sector in Bangladesh. 


\section{References}

Ahmed AU (2000) Trends in consumption, nutrition and poverty. In Ahmed, R., Haggblade, S. and Chowdhury, T.E. (eds.) Out of the Shadow of Famine: Evolving Food Markets and Food Policy in Bangladesh. Baltimore: Johns Hopkins University Press.

Ahmed R, Hossain M (1990) Developmental impact of rural infrastructure in Bangladesh, Research Report No. 83. International Food Policy Research Institute, Washington, DC.

Alauddin M, Tisdell C (1995). Labour absorption and agricultural development: Bangladesh's experience and predicament. World Development 23, $282-297$.

Alauddin M, Tisdell C (1991) The Green Revolution and Economic Development: The Process and its Impact in Bangladesh. Macmillan, London.

Ali M, Byerlee D (2002) Productivity growth and resource degradation in Pakistan's Punjab: A decomposition Analysis. Economic Development and Cultural Change 50, 839-863.

Antle JM, Pingali PL (1994) Pesticides, productivity and farmer health: a Philippine case study. American Journal of Agricultural Economics 76, 418-430.

Arkin H, Colton RR (1963) Tables for Statisticians. $2^{\text {nd }}$ Edition. Harper and Row Publishers, New York.

Bumb B, Baanante, C (1996). The role of fertilizer in sustaining food security and protecting the environment to 2020. Food, Agriculture, and Environment Discussion Paper 17. International Food Policy Research Institute, Washington, DC.

Coelli TJ, Rahman S, Thirtle C (2002) Technical, allocative, cost and scale efficiencies in Bangladesh rice cultivation: a non-parametric approach. Journal of Agricultural Economics $53,607-626$. 
Crawford E, Kelly V, Jayne TS, Howard J (2003). Input use and market development in SubSaharan Africa: an overview. Food Policy 28, $277-292$.

Donovan WG (1996). Agriculture and economic reform in Sub-Saharan Africa. AFTES Working Paper No. 18, Agriculture Policy and Productivity. The World Bank, Washington, DC.

Douglas G, Michael M, Derek B (2005) Technology adoption in intensive post-green revolution systems. American Journal of Agricultural Economics 87, 1310-1316.

ESI (2007) NLOGIT-4, Econometric Software, Inc. New York.

Evenson R E, Douglas G (2003) Assessing the impact of the green revolution, 1960 to 2000. Science 300, $758-762$.

FAO (1994). Structural adjustment and the provision of agricultural services in sub-Saharan Africa. Food and Agriculture Organization of the United Nations, Rome.

Freebairn DK (1995) Did the green revolution concentrate incomes? A quantitative study of research reports. World Development 23, 265-79.

Hazell PBR, Ramasamy C, Aiyasamy PK (1991) The Green Revolution Reconsidered. The Impact of High Yielding Varieties in South India. New York: John Hopkins University Press.

Hossain M (1989) Green Revolution in Bangladesh: Impact on Growth and Distribution of Income. Dhaka: University Press Ltd, 1989.

Hossain M, Quasem MA, Akash MM, Jabber MA (1990) Differential Impact of Modern Rice Technology: The Bangladesh Case. Dhaka: Bangladesh Institute of Development Studies.

Islam T, Taslim MA (1996) Demographic pressure, technological innovation and welfare: the case of the agriculture in Bangladesh. Journal of Development Studies 32, 734 - 770. 
Janaiah A, Otsuka K, Hossain M (2005) Is the productivity impact of the green revolution in rice vanishing? Economic and Political Weekly 40, 5596-5600.

Ladha JK, Dawe D, Pathak H, Padre AT, Yadav RL, Singh B, Singh Y, Singh Y, Singh P, Kundu AL, Sakal R, Ram N, Regmi AP, Gami SK, Bhandari AL, Amin R, Yadav CR, Bhattarai EM, Das S, Aggarwal HP, Gupta RK, Hobbs PR (2003) How extensive are yield declines in long-term rice: Wheat experiments in Asia? Field Crops Research 81, $159-180$.

Lipton M, Longhurst R (1989) New Seeds and Poor People. London: Unwin Hyman.

MOA (2008) Handbook of Agricultural Statistics of Bangladesh, December 2007. MOA, Government of Bangladesh, Dhaka. Available at http://www.moa.gov.bd/statistics/ statistics.htm (last accessed July 31, 2008).

Otsuka K (2000) Role of agricultural research in poverty reduction: lessons from the Asian experience. Food Policy 25, 447-462.

Palmer-Jones R, Parikh A (1998). The determination of agricultural wage rates in Bangladesh. Journal of Agricultural Economics 49, 111-113.

Payton, RW, Barr JJF, Martin A, Sillitoe P, Deckers JF, Gowing JW, Hatibu N, Naseem SB, Tenywa M, Zuberi MI (2003). Contrasting approaches to integrating indigenous knowledge about soils and scientific soil survey in East Africa and Bangladesh. Geoderma 111, 355-386.

Pimentel D (1996) Green revolution and chemical hazards. The Science of the Total Environment 188 (Supplement 1), S86-S98.

Pingali PL, Hossain M, Gerpacio RV (1997) Asian rice bowls: The returning crisis. Wallingford: CABI. 
Rahman S (1998) Socio-economic and environmental impacts of technological change in Bangladesh agriculture (PhD Dissertation). Asian Institute of Technology, Bangkok.

Rahman S (1999) Impact of technological change on income distribution and poverty in Bangladesh agriculture: an empirical analysis. Journal of International Development 11, $935-955$.

Rahman S (2002) Technological change and food production sustainability in Bangladesh agriculture. Asian Profile 30, 233 - 246.

Rahman S (2003) Farm-level pesticide use in Bangladesh: determinants and awareness. Agriculture, Ecosystems and Environment 95, 241-252.

Rahman S (2010) Six decades of agricultural land use change in Bangladesh: effects on crop diversity, productivity, food availability and the environment, 1948-2006. Singapore Journal of Tropical Geography 31, 254-269.

Rahman S, Parkinson RJ (2007) Soil fertility and productivity relationships in rice production system, Bangladesh. Agricultural Systems 92, 318-333.

Reardon T, Barrett C., Kelly V, Savadogo K. (1999). Policy reforms and sustainable agricultural intensification in Africa. Development Policy Review 17, 375-395.

Redclift M (1989) The environmental consequences of Latin America's agricultural development: some thoughts on the Brundtland Commission Report. World Development 17, 365-377.

Rosegrant MW, Paisner MS, Meijer S (2001). Global food projections to 2020: emerging trends and alternative futures. International Food Policy Research Institute (IFPRI), Washington, DC.

Salim R, Hossain A (2006). Market deregulation, trade liberalization and productive efficiency in Bangladesh agriculture: an empirical analysis. Applied Economics, 38, 2567-2580. 
Shiva V (1991) The Violence of the Green Revolution: Third World Agriculture, Ecology and Politics. London: Zed Books.

Singh RB (2000). Environmental consequences of agricultural development: a case study from the Green Revolution state of Haryana, India. Agriculture, Ecosystem and Environment. 82: $97-103$.

SRDI (Soil Guides for Crop Production) (1991) (in Bangla). Dhaka: Soil Resource Development Institute, 1991.

STATA Corp. (2003) STATA Statistical Software Release 8.0. Stata Corporation, College Station, TX.

Tsubota, K. (2002). Views on food production: towards a new Green Revolution. Paper presented at the 13th International Farm Management Congress, Wageningen, The Netherlands, July 7-12, 2002.

Wolf EC (1986) Beyond the green revolution: new approaches for third world agriculture. Worldwatch Paper No. 73. Washington, D.C.: World Watch Institute. 
is

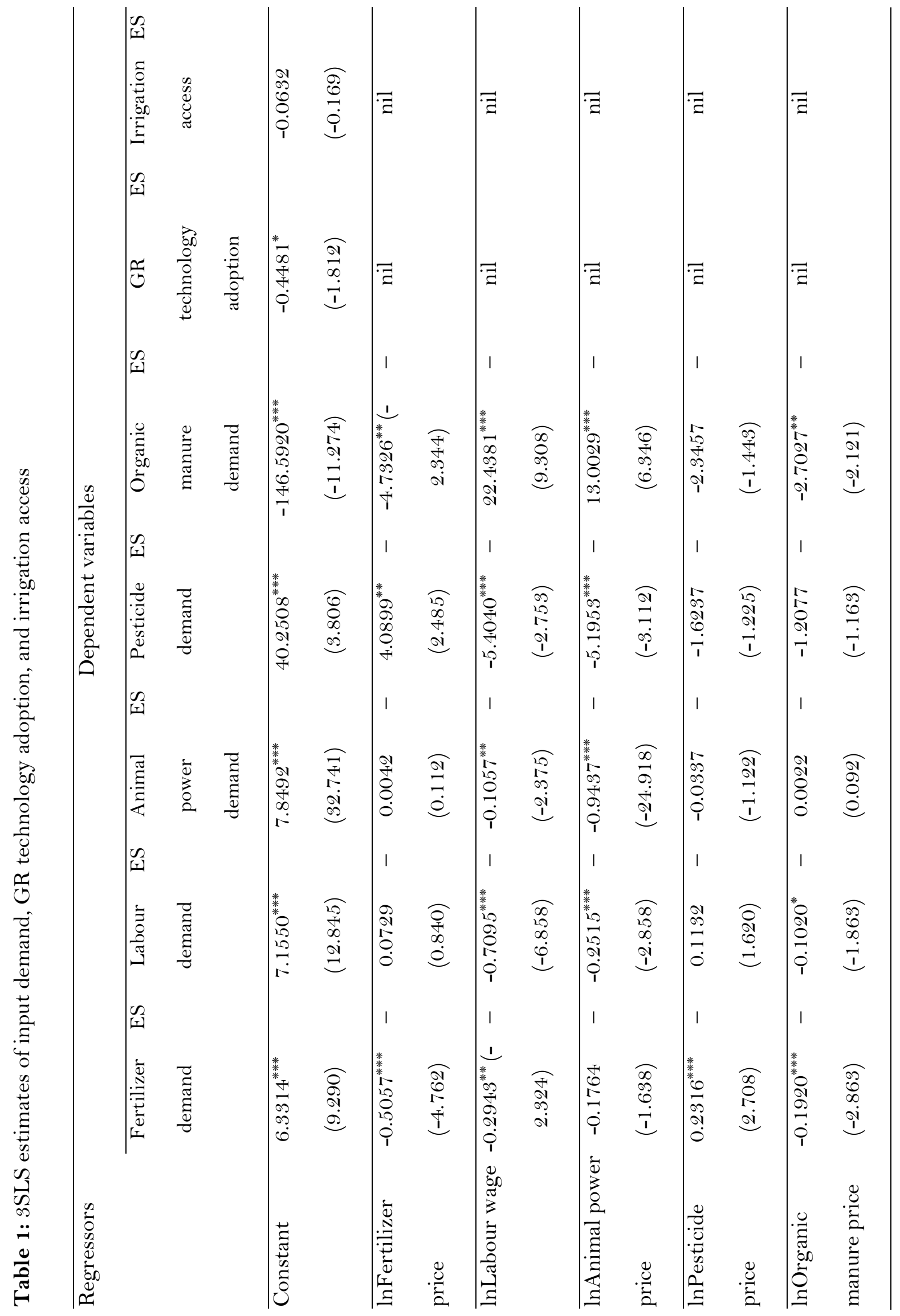




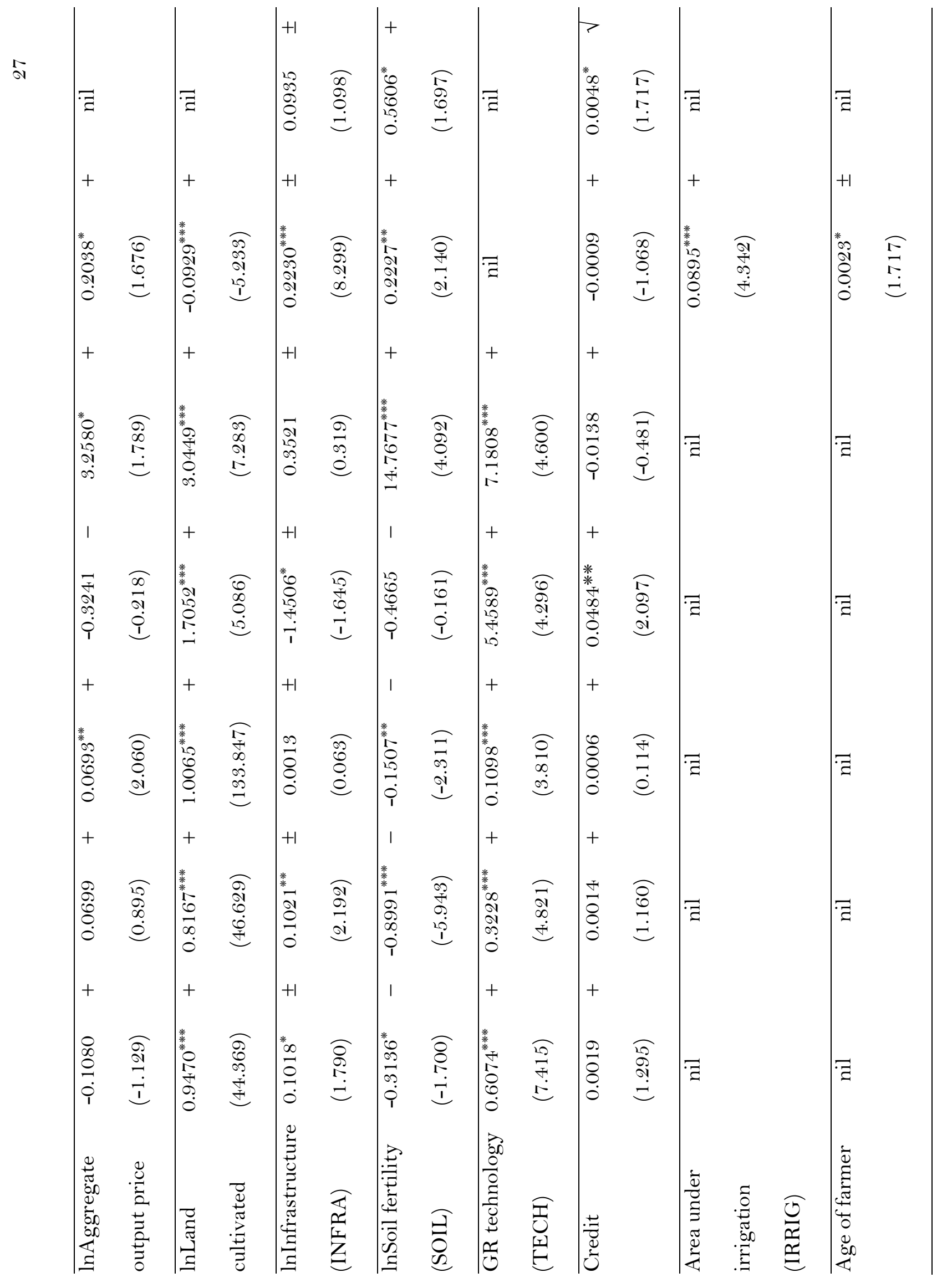




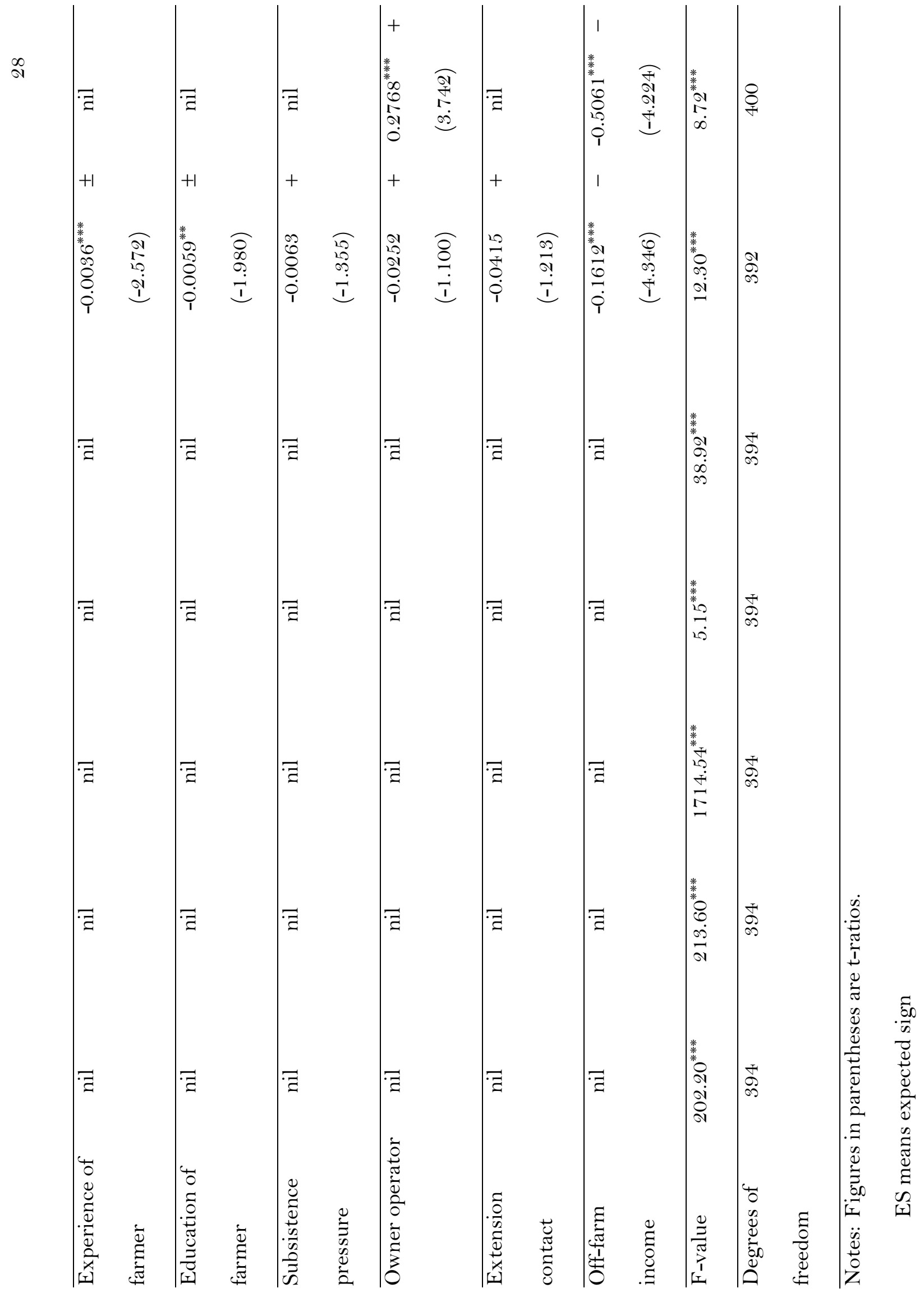




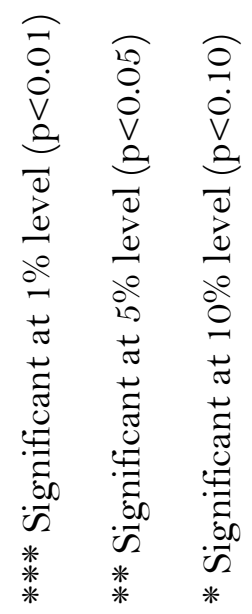


${ }^{1}$ The GR is a 'technology package' comprising material components of improved high-yielding varieties (HYVs) of major staple cereals (rice and wheat), irrigation or controlled water supply and improved moisture utilization, fertilizers and pesticides and associated management skills (Tsubota 2002)

${ }^{2}$ Early Green Revolution period covers from 1961 to 1980 and late Green Revolution period covers from 1981 to 2000 (Evenson and Douglas 2003).

${ }^{3}$ The sample households were selected based on the information on the total number of households including their land ownership categories, which were obtained from BRAC (a national non-governmental organization). Then a stratified random sampling procedure was applied using a formula from Arkin and Colton (1963) that maximizes the sample size with a $5 \%$ error limit. Farm size categories (large, medium, and small farmers) were used as the strata (for details, see Rahman 1998).

${ }^{4}$ The crop groups are: (1) traditional rice varieties (Aus - pre-monsoon, Aman - monsoon, and Boro - dry seasons); (2) modern/high yielding rice varieties (Aus, Aman, and Boro seasons); (3) modern/high yielding wheat varieties; (4) jutes; (5) potatoes; (6) pulses (include lentil, mungbean, and gram); (7) spices (include onion, garlic, chilly, ginger, and turmeric); (8) oilseeds (include sesame, mustard, and groundnut); (9) vegetables, eggplant, cauliflower, cabbage, arum, beans, gourds, radish, and leafy vegetables); and (10) cotton.

${ }^{5}$ In order to enable estimation of a linear system of equations, the necessary condition for identification of an individual structural equation is as follows: if $m_{i}>\left(K-k_{i}\right)$, then the equation is under-identified and cannot be estimated; where, mi is the number of endogenous variables in an individual structural equation; $k_{i}$ is the number of exogenous variables in the same structural equation; and $K$ is the total number of exogenous variables in the system (STATA Corp. 2003). 
In this system of structural equations, the value of $m_{i}$ in each model is one. Meanwhile the value of $\left(\mathrm{K}-\mathrm{k}_{\mathrm{i}}\right)$ in all the demand functions are 7 , in the TECH model is 6 and in the irrigation access model is 13. Therefore, the identification condition is satisfied and the system as a whole is over-identified and can be estimated.

${ }^{6}$ Data on cultivated area and production were collected separately for traditional and HYV rice for each of the three growing seasons (i.e., Aus, Aman and Boro) and also for traditional and HYV wheat.

${ }^{7}$ This definition of GR technology indicator is widely used in the seminal studies of GR and its impacts in Bangladesh (e.g., Hossain 1989; Hossain et al. 1990; and Ahmed and Hossain 1990). The measure takes into account multiple cropping of a given area over a calendar year.

${ }^{8} 1 \mathrm{US} \$=43.89$ Taka $(1997)$

${ }^{9}$ A composite 'index of underdevelopment of infrastructure' was constructed using the cost of access approach. A total of 13 elements are considered for its construction. These are primary market, secondary market, storage facility, rice mill, paved road, bus stop, bank, union office, agricultural extension office, high school, college, Thana (sub-district) headquarters, and post office. A total $\operatorname{cost}(T C)$ of access was computed by summing up individual costs $\left(I C_{i}\right)$ of access (i.e., distance $\mathrm{x}$ cost per $\mathrm{km}$ ). Then, $T C$ was correlated with costs for each element $\left(I C_{i}\right)$ which provided individual correlation coefficients $\left(W_{i}\right)$. The final index (INFRA) was then calculated by summing up all the ICs (each weighted by its correlation coefficient) and divided by the sum of all correlation coefficients (see Ahmed and Hossain 1990 for further details).

10 The 'soil fertility index' was constructed from the test results of soil samples collected from the study villages. Ten soil fertility parameters were tested; these are soil $\mathrm{pH}$, available nitrogen, available potassium, available phosphorus, available sulphur, available zinc, soil texture, soil organic matter content, cation exchange capacity of soil, and electrical 
conductivity of soil (for details of sampling and tests, see Rahman and Parkinson 2007; and Rahman 1998). A composite weighted index of soil fertility was constructed using a Likert type scale. First, each of the soil parameters were categorized into 'high', 'medium' or 'low' level following the guideline provided by the Soil Resources Development Institute (SRDI) of Bangladesh, which assigns these categories based on a range of values of each soil parameter required for crop growth (SRDI 1991). Then, the soil fertility index was constructed by summing up the index of each soil parameter, divided by the total number of parameters used in the computation.

${ }^{11}$ This index is constructed as the 'underdevelopment of infrastructure'. Therefore, a positive sign on the coefficient of this variable implies a negative impact on the input demands and viceversa. 